\title{
The Situational Impact of Brand Image Beliefs
}

\author{
Rajeev Batra \\ University of Michigan \\ Pamela Miles Homer \\ California State University, Long Beach
}

\begin{abstract}
This study experimentally examines some situational influences on the formation and consequences of two brand image beliefs, pertaining to fun and sophistication (classiness). It tests McCracken's (1986) meaning transfer mechanisms and establishes that nonverbalized personality associations of celebrity endorsers on these dimensions can indeed reinforce equivalent consumer beliefs about a brand's fun and classiness benefits. However, this occurs only if a social consumption context is evoked, and only if the brand image beliefs are appropriate to the consumer schema for the product category involved. Moreover, under these facilitating conditions, such ad-created brand image beliefs have an impact only on brand purchase intentions and not on brand attitudes. Results have implications for the growing literature on different types of brand imagery associations, as well as for future research on the processing of nonverbal stimuli, the measurement of nonfunctional brand beliefs, and consumer inference processes.
\end{abstract}

Certain brands (e.g., Coca-Cola, McDonald's) are considered to possess "high brand equity," resulting in higher market shares and prices than competing products (Badenhausen, 1996). They typically have high customer loyalty, name awareness, perceived quality, strong brand associations, and other assets (Aaker, 1991). A key reason for their strength is the existence of favorable, strong, and unique associations about them in consumers' memories (Keller, 1993).

This article studies the formation and consequences of one category of these brand associations in memory, those dealing with beliefs about the personality or image of the brand. These brand image beliefs include all the associations that consumers connect with the brand, including but going beyond brand personality associations (see Batra, Lehmann, \& Singh, 1993, pp. 83-84, for a discussion). ${ }^{1}$ Many of the brand associations that make brands distinctive and strong are of this nonfunctional type; that is, they go beyond the perceived quality of the brand on functional product and service criteria and deal instead with "intangible" properties of the

Requests for reprints should be sent to Rajeev Batra, D6212 Davidson Hall, School of Business Administration, University of Michigan, Ann Arbor MI 48109. E-mail: rajeevba@umich.edu

'A similar term, brand personality, typically refers to "the set of human characteristics associated with a brand" (Aaker, 1997, p. 347). In some of the other literatures discussed later, these associations are also described as brand meanings. brand (e.g., Coca-Cola is "All-American," Mercedes is "prestigious," etc.). ${ }^{2}$ (See Aaker, 1997, for a discussion of types and dimensions.)

Little is formally known about the processes by which ads create brand image beliefs, the moderators that limit this creation, and their impact on brand preference. Although McCracken (1986, 1989) conceptualized the implications of meaning transfer and celebrity endorsement for brand image beliefs, the mechanisms he postulated have not been verified experimentally. This article reports a study that experimentally investigates the reinforcement by ad endorsers of two specific brand image beliefs concerning fun and sophistication, and of their impact on brand preferences. We test the moderating roles of a social consumption context and of

\footnotetext{
${ }^{2}$ The distinction we draw here between functional and nonfunctional is somewhat analogous to that drawn by Holbrook (1978) between factual (tangible and verifiable) and evaluative (intangible and subjective) beliefs; by Batra and Ahtola (1990) between utilitarian and hedonic attributes; and by Myers and Shocker (1981) between functional and user-imagery attributes (for a review, see Lefkoff-Hagius \& Mason, 1993). We are not claiming that the beliefs we are labeling nonfunctional do not often have their origin in physical/objective properties (e.g., a product's texture might add to the felt pleasure in its consumption and a car's metal bodywork might create a sense of style). Rather, we are drawing a distinction between functional beliefs on the one hand (about utilitarian, economic, rational attributes or benefits) and those that are nonfunctional (about either hedonic/sensory/experiential properties, or social/sign-value/personality/image) on the other.
} 
product category schema "fit" in the reinforcement and impact of these brand image beliefs (differentially on measures of brand attitudes and purchase intentions).

\section{LITERATURE AND HYPOTHESES}

\section{Formation of Brand Image Beliefs}

A brand can acquire cultural meaning in a multitude of ways: the kinds of users typically associated with it, its employees or chief executive officer, its product-related attributes, packaging details, product category associations, brand name, symbol, advertising message and style, price, distribution channel, and so forth (Aaker, 1997, p. 348; Batra et al. 1993, p. 93). Although other streams of research are also helpful in understanding the general process through which these associations supposedly get formed (such as classical conditioning, see Shimp, 1991, for a review; or semiotics, see Mick, 1986, for a description), McCracken's meaning transfer model, drawing from cultural anthropology and ethnography, is arguably the most influential.

McCracken (1986) argued that advertising (among other means) can be used to transfer a particular kind of cultural meaning from the outside world to a brand. An ad can bring together the brand and some other widely accepted symbol of a particular kind of cultural meaning (e.g., the appropriate tone, pace, camera direction, voice-overs, etc.) in such a way that the ad's viewer or reader sees an essential similarity between the two, and that particular kind of cultural meaning (e.g., gender, age, social class, ethnicity) then becomes a part of the brand (McCracken, 1990). McCracken used this model (1989) to show how endorsers can be seen as conduits of cultural meaning transfer. Using endorsers is clearly a very common method of building a brand's associations and it is therefore the method we use in our experimental study. Endorsers have traditionally been thought of as sources of the information in the ad, contributing to the acceptability of the content of (arguments in) the message because of the source's credibility or attractiveness (cf. Hovland, Janis, \& Kelley, 1953). According to McCracken's meaning transfer model, however, brands benefit from associations with endorsers because the endorsers acquire or possess particular configurations of desirable cultural meanings (e.g., Pepsi becomes more attractive to teenagers when endorsed by Madonna because of her anti-establishment image). Thus past investigations of the processes by which endorser qualities of attractiveness or expertise have their persuasive effects (e.g., Kahle \& Homer, 1985; Kamins, 1990) do not provide evidence concerning the transfer of cultural meaning from endorsers into brands. Indeed, although McCracken's $(1986,1989)$ model of the meaning transfer process is by now widely accepted on the basis of ethnographic analysis, there has not to our knowledge been any previously published experimental evidence of this process.
Our study provides this evidence. Importantly, we believe that these experimental effects will be significantly moderated by the variables highlighted later.

\section{Moderating Role of Product Category Schema Fit in the Creation and Impact of Brand Image Beliefs}

First, we suggest that for these brand image beliefs to be evoked and influence brand preferences, the beliefs need to fit the consumer's "schema" for the product category and the usage occasion. Aaker (1999) recently showed that specific brand personality aspects or dimensions only have an impact on a consumer's brand preference if those personality traits are both descriptive of and important to that consumer's sense of her own personality or self. These self-schematic traits can be either chronically accessible to the individual or become temporarily accessible because of salient situational cues.

Here, we extend Aaker's (1999) schematicity framework. Just as different social situations can make different self-conceptions more salient for an individual (Aaker, 1999, p. 46), different consumption occasions (involving different product categories, embedded within different usage occasions) could also influence the salience of symbolic benefits (and thus brand image beliefs). Greater salience of these benefits might increase the ease of forming endorser-based brand image beliefs - and then lead to differential effects on preference.

Researchers have documented the fact that different product categories and/or usage occasions vary in the salience of specific nonfunctional qualities. According to Lautman (1991), consumers act as if they have a schema for different products or services. That is, they form clusters of interconnected rational and irrational beliefs, emotions, facts, and perceptions that are stored in memory as a unit. Durgee and Stuart (1987) pointed out that the end-affect associations desired by consumers are often a characteristic of the product category, such as fun in the case of ice cream. Domzal and Kernan (1992) analyzed 321 print ads for four product categories using a semiotic framework and found that beer ads typically played up the category associations of refreshment, friendship and social consumption, a sense of private enjoyment, and communicating status, whereas liquor ads stressed a sense of solitude and relaxation, extroverted festive celebration, as well as status communication.

Levy (1986) suggested that a "primary source of meaning is the product (category) itself," giving examples, within the beverage category, of how liqueurs can mean discrimination, wine snobbism, beer sociability and democracy, soup tradition, and juices virtue. "Drinking stronger beverages is seen as more mature, higher status, and also as masculine: strong coffee compared with weaker and more feminine tea" (pp. 216-217). Elsewhere, Levy (1981, p. 55) documented how specific foods are associated with specific kinds of users 
(e.g., chunky peanut butter for boys, smooth for girls; lamb chops and salads for women, steaks for men). Thus the type of food or beverage — not just its specific brand-will affect the salience of specific cultural meanings.

If the nature of the specific product category and consumption occasion can make different cultural meanings more salient and desirable from a self-definition or public presentation perspective, it should affect both the transfer of these meanings from sources such as endorsers and the subsequent situational impact of a brand's imagery beliefs on preference. Anecdotal and journalistic evidence of the necessity of brand personality imagery to be "schema-relevant" to the product category, given the specific situation in which it is being used, can also be found in many of the brand-history cases presented by various authors (e.g., Cleary, 1981; Darden, 1990; Randazzo, 1993). For instance, Coca-Cola's "happy pleasure" associations appear to be obviously relevant to why and when consumers drink soft drinks. Mothers buying baby foods, soups, and other products for their children and families are obviously using it in the context of their roles as nurturers, so the nurturance associations of Campbell Soup, Gerber, and others are right on target. Ivory soap needed to compete with other products (such as the imported Castile soaps) on purity and mildness. These associations were exactly what its good-enough-for-babies imagery created for it. Sporting products are bought by consumers who want to be competitive and "winning," and want to identify with leading athletes, desires leveraged by Nike.

Thus, going beyond Aaker's (1999) evidence for the important role of the individual consumer's (or target segments') self-schemas in moderating the impact of brand image beliefs, we are researching here the role of the product category itself, which we believe should also be an important moderator in the formation and the impact of such beliefs. We thus hypothesize first that the personality associated with an endorser, in an ad for a brand, should be more likely to reinforce (and, in some cases, create) related personality beliefs about the brand if they are "schematic" for the product category of which the brand is a part, given the specific usage or consumption situation being considered:

H1: A celebrity endorser's personality attributes will lead to stronger brand image beliefs if these attributes are relevant to the schema held by consumers for that product category and the specific use being considered for it.

The moderating role of category-schema fit is also likely to emerge in the impact (consequences) of these brand image beliefs for brand preference. For these beliefs to have meaningful consequences for brand preference they must again fit the product or service category, by being seen as relevant to the reasons for purchase and consumption. Although this contingency might seem self-evident, it has not been stressed adequately in the existing literature (Aaker, 1991, p. 161, is an exception). That is, the brand image beliefs being created should add value to the consumption experience for that product category and consumer segment to influence brand choice. Put another way, they must be seen as being diagnostic to the ultimate utility that will be gained through purchase and consumption (cf. Lynch, Marmorstein, \& Weigold, 1988). For instance, it could be argued that a mother feeding food to her children is looking not only for nutrition and taste but also the feeling of being, and being seen as, a nurturing mother. Similarly, a consumer buying over-the-counter medicines may be seeking a feeling of confidence (from efficacy) and safety. A purchasing agent for a company buying a million-dollar piece of equipment may be seeking satisfaction that this is a no-risk decision. (As the apocryphal saying goes, customers often bought IBM simply because "no one got fired for buying IBM.") A young man buying beer might be seeking peer-group recognition for being quite the party animal. In these examples, therefore, the key desired "category-relevant" associations would be nurturance, safety or confidence, or a wild-edged sense of hedonic mayhem, and brands that elicit stronger beliefs about these attributes would be preferred. It is well documented that, even within the same product category, brands vary in the extent to which they are seen as possessing these personality attributes. For instance, within soft drinks, Pepsi is widely seen as being younger and more exciting, Coke as more "real," and Dr. Pepper as more nonconforming and fun (Aaker, 1997, p. 348). We thus hypothesize that:

H2: Ad-evoked brand image beliefs will have a greater impact on brand preferences when they fit consumer schemas about the benefits derived from the product category.

\section{Moderating Role of Social Visibility in the Purchase/Consumption Occasion}

Prior research has also shown that a brand's image-relevant attributes are more important in situations in which the product is consumed publicly (e.g., Bearden \& Etzel, 1982). Such nonfunctional associations are likely to be more important in determining consumer preference when products are purchased for self-expressive and symbolic purposes. In these situations, purchase and consumption are at least partly motivated by a need for public self-presentation and impression management (Aaker, 1999) or for private enhancement of one's self-definition (Belk, 1988, p. 152; McCracken, 1986, p. 80). Because brand image beliefs usually pertain to socially visible aspects of a brand (e.g., how classy or sophisticated it is widely perceived to be), the creation and impact of these beliefs ought to be greater in purchase/consumption occasions where social desirability needs are more salient or stronger (i.e., where impression management needs are higher, cf. Fishbein \& Ajzen, 1975; Snyder \& DeBono, 1985). Therefore: 
H3: Ad-reinforced brand image beliefs will have a greater impact on brand preferences in purchase or consumption situations where social and impression management needs are higher.

\section{Effects on Intentions versus Attitudes}

To reiterate, a brand's image plays a role in brand preference because it adds to the self-expressive and symbolic value of the brand for the buyer (Aaker, 1999), and thus to that buyer's impression management efforts (cf. Tetlock \& Manstead, 1985). This is why a buyer's level of self-monitoring has been found to moderate the impact of brand image beliefs on displayed brand preference (Aaker, 1999; Gangestad \& Snyder, 1985). Thus, such beliefs should have greater impact on intentions to purchase and consume brands (behavior that others can observe) than on brand attitudes (which are private and unobservable). Therefore:

H4: Brand image beliefs will contribute more to brand purchase intentions than to brand attitudes.

In summary, our theoretical framework argues that using celebrity endorsers in an ad should lead consumers to develop stronger brand image beliefs when the endorser's personality fits the image associated with the type of product being advertised (H1). These ad-created or reinforced beliefs should then impact brand preference more strongly when the celebrity personality association fits the desired consumer hedonic or image benefits from that product category $(\mathrm{H} 2)$; when the consumption situation contains high social and impression management needs $(\mathrm{H} 3)$; and when the measures of brand preference are purchase intentions rather than attitudes (H4). It is not clear a priori whether the last three moderating effects operate independently, or whether all are jointly necessary for ad-created brand personality beliefs to impact brand preference. Our study investigates these possible interrelations.

\section{METHOD}

\section{Overview}

Our goal in this pair of experiments thus was to expose participants to an ad for a brand, in one of two product categories, featuring a likable celebrity endorser with certain (pretested) personality associations. These celebrity associations would not be mentioned explicitly (verbally) in the ad. To ensure that we were testing the effects of endorser personality and not endorser attractiveness (and thus not merely replicating previous studies such as Kamins, 1990, or Kahle \& Homer, 1985), we sought to use endorsers who were equally attractive but differed in their pretested personality relevance with two product categories. These endorser personality as- sociations would either fit or not fit the product category schema about benefits sought from that category, again as revealed through pretests (cf. $\mathrm{H} 1, \mathrm{H} 2$ ).

We initially intended to test $\mathrm{H} 3$ (the moderating effect of higher impression management needs on the effect of brand image beliefs on brand preference) via an individual-difference variable called the susceptibility to normative influence (SNI; Bearden, Netemeyer, \& Teel, 1989). The effects of this variable in Experiment 1, however, were not significant. We therefore conducted a second study in which the social consequences of product purchase were raised experimentally. The two experiments in combination composed a $2 \times 2 \times 2$ (Consumption Context: High vs. Low in Social Consequences $\times$ Product Category: Relevant or Irrelevant $\times$ Product Endorser at two levels: Relevant Positive Celebrity or Irrelevant Positive Celebrity) between-subjects factorial design. For reasons that will be discussed later (when $\mathrm{H} 1$ is tested), we also added two no-endorser control conditions to each experiment that presented the brand's standard logo instead of the celebrity endorser's picture.

\section{Pretests of Manipulations}

Because of space limitations, only the key results of the two pretests are presented here. (Full details, including means and all statistical tests, are available from Rajeev Batra.)

To elicit product category schemas, 35 undergraduate participants were asked to write down whatever associations they had with certain snack foods (such as ice creams and candy bars). Analysis revealed the following major themes: calories, cavities, cholesterol, fat, sugar (i.e., health-related associations); taste/sweetness/texture; specific attributes or benefits (e.g., energy, hunger, nuts, chocolate, peanut butter); fun/enjoyment; and various brands and occasions (such as eating by oneself or serving others at parties).

The second pretest, involving 41 undergraduates, helped us select among appropriate snack food product categories (e.g., ice cream, potato chips, cookies), relevant product category "nonfunctional" (image) associations (e.g., fun, sensible, sophisticated), and positively rated and personality-appropriate media celebrity endorsers (from among Roseanne Barr, Whoopi Goldberg, Meryl Streep, and Barbara Walters). The participants rated four brands (Breyers Ice Cream, Ruffles Potato Chips, Snackwell's Low-fat Cookies, and Pepperidge Farm Cookies) along nine 7-point bipolar scales designed to represent three dimensions: fun, sophisticated, and sensible. Each respondent also rated each celebrity on similar items and rank-ordered the fit between each celebrity and each brand. Results showed that Ruffles Potato Chips were rated as more fun than sophisticated, and less sophisticated than Pepperidge Farm cookies.

In the celebrity personality ratings, Barbara Walters was rated as being more sophisticated, more dependable, and less fun than either of the other celebrities; she was also rated as being more sophisticated than fun and more dependable than 
sophisticated. On the other hand, Roseanne Barr was perceived as being more fun than sophisticated or dependable. According to the rank orderings, Barbara Walters was clearly perceived to be the celebrity endorser best matched with Pepperidge Farm Cookies and Roseanne Barr was rated as being best matched with Ruffles Potato Chips. Walters was associated with sophistication and classiness, but was not perceived as being spirited, fun, and lower class, suggesting a match to expensive cookies such as Pepperidge Farm. In contrast, Barr was rated as having an image of being fun/spirited, lower class, unsophisticated, thus providing a match to Ruffles potato chips.

Both experiments reported later used identical procedures and manipulations, with the exception of the "high social consequences" manipulation used in Experiment 2.

\section{Participants}

Participants were undergraduate students (both sexes, ages 18-22), assigned randomly to the different conditions: 181 participants took part in Experiment 1 and 86 took part in Ex-
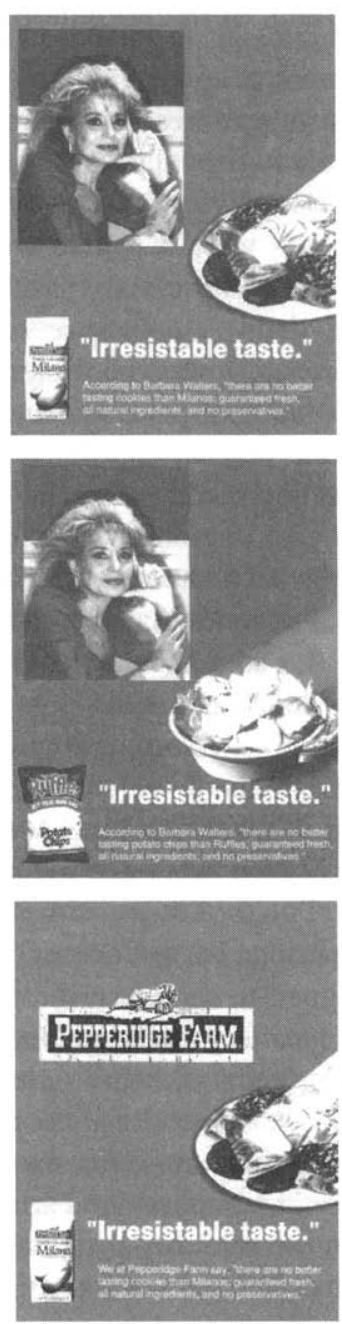

periment 2. Participants who provided incomplete or inconsistent data that, if included, would have greatly reduced the reliabilities of key measures, were dropped from the analysis ( $n=8$ in Experiment 1, $n=10$ in Experiment 2). Analysis of the demand characteristic question showed no evidence that participants knew the underlying purpose of the experiment.

\section{Design and Manipulations}

The $2 \times 2$ factorial design used two between-subjects factors: product category (two levels, cookies versus potato chips) and product endorser (two levels, relevant positive celebrity versus irrelevant positive celebrity). Two no-endorser control cells were also used. Snack food ads were utilized as the information source: they contained either verbal functional attribute information for the product category (chips or cookies) with a positive celebrity endorser relevant or irrelevant to that product category; or that same information with the brand's logo instead of the celebrity endorser (control cells).

The four test and two control ads appear in Figure 1. Each ad (in black and white) featured (a) a large visual of either the
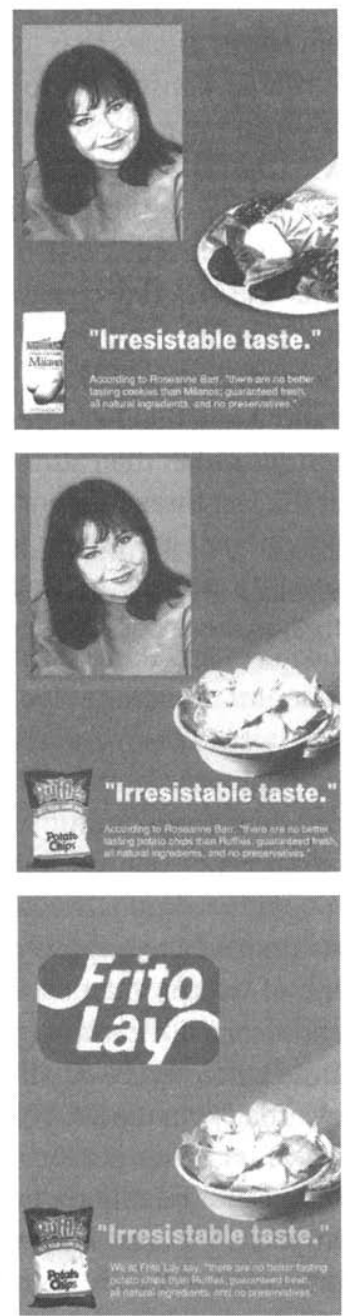

FIGURE 1 Test ads used in Experiments 1 and 2. 
smiling face of Roseanne Barr or Barbara Walters, (b) a package shot of either Pepperidge Farm Milano cookies or of Frito Lay Ruffles potato chips, (c) a visual of a plate full of either the cookies or the potato chips, as appropriate, and (d) the headline plus body copy. The headline declared "Irresistible Taste" and the body copy said "According to Roseanne Barr (Barbara Walters), there are no better tasting cookies (potato chips) than Milanos (Ruffles); guaranteed fresh, all natural ingredients, and no preservatives." The control cells were similar, except that they replaced the face of these endorsers with the brand logo of either Pepperidge Farm or Frito Lay and used text that began "We at Pepperidge Farm (Frito Lay) say..."

\section{Procedure}

Each respondent performed the various experimental tasks in a self-paced classroom setting. Participants were merely told that these different "Consumer Research Studies" dealt with their opinions about certain advertisements and brands. The various sets of measures were presented as three ostensibly independent studies. In the first, "Advertising Pretest" study, participants were told to read the "test advertisement." They then viewed the experimental ad (for as long as they wished) before answering the dependent measures. Participants in the control conditions saw the control ads for the brand in their category (featuring the brand logo) instead of an experimental ad (using a celebrity endorser). In the second, "Product Category Associations" study, participants were asked to perform a word association task and indicate the strength of association between either potato chips or cookies (the product category not used in the particular ad they had just rated) and a set of six words (i.e., fun, outgoing, classy, playful, cosmopolitan, and sophisticated). The third ("Personality") study was composed of five sets of personality evaluations. Each participant rated Barbara Walters, Roseanne Barr, himself/herself, Pepperidge Farm, and Frito Lay on various personality scales to be described presently.

The procedure and manipulations in Experiment 2 were identical to those in Experiment 1, with the crucial difference that in the second experiment the social/impression value of the consumption occasion was heightened. This was accomplished in three ways. First, we added a statement to the manipulation to say that these snack products were being purchased by the student participants for $a$ party, to increase the social visibility of the consumption context. This was done in the ostensible "Study 1" portion of the procedure; they were now told to "assume you are considering buying some food items for a party that you will host soon," before they were asked to read the "test advertisement for a leading national brand of a food product." Second, the questions asking for the importance of the attribute beliefs in choosing a brand in that category (to be described in the next section) were now prefaced by the phrase, "for a party that you are hosting." Finally, the purchase intentions question (see later) was prefaced with the phrase "When you decide which brand of (packaged cookies/potato chips) you buy for a party you are hosting," to increase the strength of the manipulation. No other changes were made to the procedure. Some possible issues associated with this manipulation are raised in the Discussion section.

\section{Measures}

The key measures were collected in "Study 1" using 7-point interval scales. Brand beliefs were measured first, using multiple items for taste (great vs. awful, fresh vs. stale, good vs. bad, great vs. awful texture), health (preservative-free vs. not; natural vs. not, natural vs. artificial ingredients), class/sophistication (is/not classy, is/not sophisticated), and fun (is/not fun; is/not playful). Importance ratings of these beliefs (not at all important/very important) were collected next. These were followed by standard assessments of overall brand attitudes (good/bad, favorable/unfavorable, positive/negative), and purchase intentions for this brand during their next purchase of cookies or chips (very likely/not likely, would certainly buy/would certainly not buy, would surely buy/would not surely buy).

Manipulation checks were then obtained in the next two studies. In "Study 2", all participants rated how strongly the other product category was associated with fun and sophistication. This was done along 7-point semantic differential scales pertaining to playful, outgoing, fun for fun; and classy, cosmopolitan, sophisticated for sophistication. To reduce ambiguity about possible subtypes within the potato chips and cookies product categories, the two product categories were described as "potato chips of the Ruffles type" and "cookies of the Pepperidge Farm type." In "Study 3", all respondents rated both product categories and brands, and both endorsers, on multiple personality descriptors for "fun" and for "sophistication" (playful, outgoing, fun; cosmopolitan, glamorous, sophisticated). The multiple items for each scale/construct were then averaged; tests of internal consistency yielded coefficient alphas that were almost all in the .74-.92 range; the exceptions were Study 3 personality ratings of Barbara Walters on fun $(\alpha=.59)$ and sophistication $(\alpha=.72)$.

\section{RESULTS}

\section{Manipulation Checks}

Table 1 provides means and standard deviations for the manipulation check scales from both experiments. To test the notion that only relevant brand imagery associations matter 
TABLE 1

Means and Standard Deviations for Manipulation Check Scales

\begin{tabular}{|c|c|c|c|c|}
\hline & \multicolumn{2}{|c|}{ Fun } & \multicolumn{2}{|c|}{ Class/Sophistication } \\
\hline & $M$ & $S D$ & $M$ & $S D$ \\
\hline \multicolumn{5}{|c|}{ Experiment 1 (low social consequences) } \\
\hline \multicolumn{5}{|c|}{ Endorser ratings } \\
\hline Roseanne Barr & $5.45_{\mathrm{a}}$ & 1.47 & $2.33_{\mathrm{b}}$ & 1.22 \\
\hline Barbara Walters & $3.57_{b}$ & 1.24 & $5.00_{\mathrm{a}}$ & 1.11 \\
\hline \multicolumn{5}{|l|}{ Brand ratings } \\
\hline Frito Lay & $5.11_{\mathrm{b}}$ & 1.43 & $2.70_{\mathrm{b}}$ & 1.11 \\
\hline Pepperidge Farm & $3.58_{b}$ & 1.40 & $3.97_{b}$ & 1.45 \\
\hline \multicolumn{5}{|l|}{ Category ratings } \\
\hline Potato chips & $4.36_{c}$ & 1.72 & $2.74_{d}$ & 1.45 \\
\hline Cookies & $3.64_{d}$ & 1.48 & $4.04_{c}$ & 1.77 \\
\hline \multicolumn{5}{|c|}{ Experiment 2 (high social consequences) } \\
\hline \multicolumn{5}{|l|}{ Endorser ratings } \\
\hline Roseanne Barr & $5.42_{a}$ & 1.17 & $2.16_{b}$ & 1.04 \\
\hline Barbara Walters & $3.85_{b}$ & 1.00 & $5.25_{\mathrm{a}}$ & 0.85 \\
\hline \multicolumn{5}{|l|}{ Brand ratings } \\
\hline Frito Lay & 5.47 & 1.18 & $2.58_{b}$ & 1.06 \\
\hline Pepperidge Farm & $3.77_{b}$ & 1.35 & $4.34_{b}$ & 1.42 \\
\hline \multicolumn{5}{|l|}{ Category ratings } \\
\hline Potato chips & $5.17_{\mathrm{c}}$ & 1.32 & $2.35_{d}$ & 1.23 \\
\hline Cookies & $3.45_{d}$ & 1.23 & $4.73_{\mathrm{c}}$ & 1.76 \\
\hline
\end{tabular}

Note. Within each column, means subscripted with a are significantly higher than those with $\mathrm{b}$; and those with $\mathrm{c}$ are higher than $\mathrm{d}$.

in raising brand preferences, it is necessary within each experiment that (a) the two product categories differ in the associations that consumers considered relevant and (b) the two endorsers differ in their ability to reinforce these target associations. It is also necessary to establish that participants perceived social consequences to be higher in Experiment 2 than in Experiment 1.

Table 1 shows that all but one manipulation succeeded in both experiments (using paired sample $t$ tests significant at $p$ $<.01$ ). "Potato chips of the Ruffles kind" were considered a more "fun" product category than "cookies of the Pepperidge Farm kind," whereas the cookies were rated a more "sophisticated" product category than potato chips. As desired, Barbara Walters was rated as less fun than Roseanne Barr, but more sophisticated than Roseanne Barr. Respondents also evaluated Barbara Walters as being more sophisticated than the Pepperidge Farm brand or the Frito Lay brand, whereas Roseanne Barr was rated as being more fun than the Pepperidge Farm brand and the Frito Lay brand. The sole manipulation failure was that in Experiment 2 Roseanne Barr was not rated higher on fun than was the control, Frito Lay brand $(M=5.47, n s)$.

Participants perceived higher social consequences in the second experiment than in the first, as intended. They also reported greater desire to purchase brands they thought others would approve of; $M=3.30$ versus $2.80, t(265)=2.38, p<$ .02 ; a greater tendency to purchase brands that observers would expect them to buy; $M=2.99$ versus $2.59, t(265)=$ $2.02, p<.05$; and greater attempts to identify with other peo- ple by purchasing the same products and brands that others purchase; $M=3.15$ versus $2.74, t(264)=2.02, p<.05$.

\section{TESTS OF HYPOTHESES}

\section{Moderated Creation/Strengthening of Brand Image Beliefs}

According to $\mathrm{H} 1$, celebrity endorsers should lead to stronger brand image beliefs in the schema-relevant category than in the schema-nonrelevant category. To test this hypothesis, we analyzed brand image beliefs (fun and class/sophistication) as a function of product category (cookies vs. chips) and endorser (Barbara Walters vs. Roseanne Barr) using pooled data from both experiments and using Experiment as an additional factor.

To determine whether the test ad endorsers raised or lowered the brand image beliefs relative to their natural levels, each participant's rating along each dimension was compared to the mean rating of a no-endorser control group in which chips and cookies ads were shown not with the two manipulated endorsers, but instead with the standard logo for the brand in question (Pepperidge Farms or Frito Lay; see Figure 1). These difference scores $\left(\mathbf{M}_{\text {diff }}\right)$ were then analyzed as a function of target category (cookies vs. chips), endorser (Walters vs. Barr), and experiment (1 vs. 2).

Note that H1 posits an interaction: for classiness, Walters' endorsement of cookies should induce stronger brand beliefs 
than Barr's endorsement, whereas for fun, Barr's endorsement of chips should induce stronger brand beliefs than Walters' endorsement. Data relevant to these predictions are shown in Table 2, which summarizes participants' ratings along each dimension as a function of endorser and product category.

Class. Pooled over experiments, Barbara Walters was more effective than Roseanne Barr in increasing brand class/sophisticated beliefs $\left(\mathrm{M}_{\text {diff }}=+.25\right.$ vs. -.13 for Walters and Barr, respectively). As hypothesized (H1), this difference was significantly greater for cookies $\left(\mathrm{M}_{\mathrm{diff}}=+.18\right.$ and -.58 , respectively) than for chips $\left(\mathrm{M}_{\mathrm{diff}}=+.31\right.$ for each endorser), $F(1,257)=4.63, p<.05$. It is important to note that these differences did not depend on the level of social consequences (i.e., experiment), $p>.10$.

Fun. We also expected that Barr would be more effective than Walters at increasing fun-related image beliefs, particularly when this characteristic was relevant to the type of product being considered. In fact, however, the effects of Barr's and Walters' endorsements on these brand beliefs did not appreciably differ and this was true regardless of whether the endorsement pertained to chips $\left(\mathrm{M}_{\text {diff }}=-.16 \mathrm{vs} .-.04\right.$, for Barr vs. Walters, respectively) or cookies ( $\mathrm{M}_{\text {diff }}=+.14$ vs. +.02 , respectively). This product category $x$ ad endorser interaction was not significant $(F<1)$, nor did it interact with experiment $(F<1)$.

All the analyses reported earlier were also repeated with two covariates - participants' prior classiness and fun beliefs about the two endorsers. This procedure controlled for the possibility that a particular participant might not be altering brand beliefs about it being classy/sophisticated simply because he never thought that Barbara Walters had these characteristics to begin with or, alternatively, believed that Roseanne Barr was classier than we anticipated. There were no changes.

\section{Attitudes and Purchase Intentions}

Analyses of brand attitudes as a function of celebrity endorser, product category, and experiment yielded no significant effects. Comparable analyses of purchase intentions also yielded no effects when participants' prior beliefs about the personalities of the two endorsers were not controlled. When these beliefs were covaried, however, a marginally significant three-way interaction occurred involving endorser, product category, and experiment, $F(1,240)=2.99, p=.085$. Barbara Walters' endorsements had little impact on intentions to purchase either cookies or chips and this was true regardless of whether social consequences (as reflected in the effects of experiment) were low ( $\mathrm{M}_{\text {diff }}=-.35$ vs. .21 , for cookies vs. chips, respectively) or high ( -.35 vs. .04, respectively). In contrast, the effect of Rosanne Barr's endorsements were contingent on social consequences. Specifically, when consequences were low, her endorsement of chips increased intentions to purchase them $\left(\mathrm{M}_{\text {diff }}=.17\right)$ but her endorsement of cookies decreased intentions to purchase them $\left(\mathbf{M}_{\text {diff }}=-.74\right)$. When consequences were high, however, her endorsement of chips had a contrast effect on purchase intentions $\left(\mathrm{M}_{\mathrm{diff}}=-.67\right)$ and her endorsement of cookies had no effect at all $\left(\mathrm{M}_{\text {diff }}=-.04\right)$.

These results indicate that the effect of endorsers on purchase intentions must be interpreted in the context of the belief-reinforcing effects of the product category's own intrinsic meanings as well as of the particular usage occasion. Our mediation analysis (to be reported presently) also shows that brand image beliefs mediate the effects of not only endorsers' personality on intentions but also impact of the product category itself.

In summary, the hypothesized interactive effects of endorser and product category were evident for only one of the two brand image beliefs—class/sophistication. Whether the lack of support for fun-related image beliefs occurred because of a weaker Roseanne Barr/fun manipulation (see Manipulation Checks section), or for some other reason, is unclear.

TABLE 2

Means for Brand Image Belief Difference (Control-Adjusted) Scales

\begin{tabular}{|c|c|c|c|c|}
\hline & $\begin{array}{c}\text { Cookies Category } \\
\text { Fun (Irrelevant) }\end{array}$ & $\begin{array}{l}\text { Cookies Category } \\
\text { Class (Relevant) }\end{array}$ & $\begin{array}{l}\text { Chips Category } \\
\text { Fun (Relevant) }\end{array}$ & $\begin{array}{l}\text { Chips Category } \\
\text { Class (Irrelevant) }\end{array}$ \\
\hline \multicolumn{5}{|c|}{ Experiment 1 (low social consequences) } \\
\hline No endorser & {$[3.37]$} & {$[5.23]$} & {$[3.49]$} & {$[2.60]$} \\
\hline Effect of Roseanne Bar & -0.01 & -0.92 & +0.15 & +0.42 \\
\hline Effect of Barbara Walters & -0.25 & -0.03 & +0.28 & +0.47 \\
\hline \multicolumn{5}{|c|}{ Experiment 2 (high social consequences) } \\
\hline No endorser & {$[3.26]$} & {$[5.57]$} & {$[4.48]$} & {$[2.91]$} \\
\hline Effect of Roseanne Barr & +0.04 & -0.24 & -0.45 & +0.21 \\
\hline Effect of Barbara Walters & -0.03 & +0.39 & -0.35 & +0.15 \\
\hline \multicolumn{5}{|l|}{ Pooled data (both experiments) } \\
\hline No endorser & {$[3.32]$} & {$[5.40]$} & [3.98] & [2.75] \\
\hline Effect of Roseanne Barr & -0.14 & -0.58 & -0.16 & +0.31 \\
\hline Effect of Barbara Walters & +0.02 & +0.18 & -0.04 & +0.31 \\
\hline
\end{tabular}

Note. Control-adjusted cell means are calculated by subtracting the relevant control group mean (in brackets) from the raw belief scale score. 


\section{Impact of Brand Image Beliefs on Brand Preference}

To test H2, H3, and H4, we employed Ordinary Least Squares regression procedures and determined the incremental impact of brand image beliefs in predicting brand attitudes and purchase intentions, over and above that due to "functional beliefs." Because many of these analyses (described later) involved interaction terms, the data for the independent variables were mean-centered prior to analysis, because otherwise interpretation of interaction terms becomes problematic (see $\mathrm{Yi}, 1990$, for a discussion of this strategy). Because we were predicting attitudes and intentions, the predictors of interest were adequacy-importance (AI) product terms (cf. Ahtola, 1975; Wilkie \& Pessemier, 1973) in which the beliefs about a particular attribute or benefit (e.g., ...is/is not great-tasting) were multiplied by the stated importance of that attribute or benefit (not at all important/very important).

The results of these analyses are shown in Table 3. Estimates are presented with the following AI predictors: the two functional beliefs concerning health and taste, the two brand image beliefs of fun and class/sophistication, a dummy variable for the product category (where chips $=-1$ and cookies = 1), and the interaction terms for this dummy times the two brand image beliefs. The last two interaction terms test the added value of the interaction between the brand image beliefs and its fit with the product category (via the dummy variable). Only these latter interactions, which are relevant to our hypotheses, will be discussed in detail.

\section{Brand Attitudes}

In Experiment 1 (Table 3, row 1), neither of the two interaction terms of the category dummy with the two brand image beliefs (fun and class AI) predictors attain significance. Thus, $\mathrm{H} 2$ does not find support in Experiment 1 (nonenhanced social consequences context) for brand attitudes. When we examine the Experiment 2 estimates (row 2), we find results similar to that for Experiment 1: the fun and class interactions with the product category are again not significant. Thus the level of social consequences does not change these results. However, the product category $(b=.26, t=2.14)$ itself is significant at $p<$ .05 , indicating attitudes toward cookies overall are higher than those for chips in this high social consequences context.

\section{Purchase Intentions}

In Experiment 1 (row 3 of Table 3), the two interactive effects of the product category and each of the two brand image beliefs (fun and class) were not significant predictors of purchase intentions. In the "higher social consequences" Experiment 2 (Table 3, row 4), however, both interactive effects were statistically reliable. The negative regression coefficient for the Fun $\times$ Category Interaction term (standardized $b$ $=-.26, t=-2.50, p<.01$ ) indicates that fun-related brand be- liefs are more important in predicting purchase intentions for potato chips than for cookies. Correspondingly, the positive coefficient associated with the Product Category $\times$ Class/Sophistication interaction $(b=.27, t=2.38, p<.05)$ implies that beliefs about sophistication contributed more toward the intent to buy cookies than to buy chips (cookies were coded as 1). Therefore, $\mathrm{H} 2$ was supported only when social consequences were relevant (Experiment 2).

The greater effect of brand image beliefs on purchase intentions in Experiment 2 compared to Experiment 1 is consistent with $\mathrm{H} 3$, which asserts that the effect of ad-reinforced brand image beliefs on brand preferences is greater under conditions of higher concern with the social consequences of purchase decisions. To test this hypothesis more formally, we conducted an additional analysis in which an experiment variable (coded as -1 and +1 for Experiment 1 and Experiment 2, respectively) and its interactions with the other independent variables were included as predictors. Thus, significant interactions with this "Experiment" variable indicate that the coefficient for the associated independent variable differed statistically across the two experiments.

Analyses of brand attitudes yielded no significant effects involving these additional predictors. However, analyses of purchase intentions indicated that the interaction of product category and classiness brand beliefs was significantly contingent on experiment $(b=.16, t=1.96, p=.05)$ and that the interaction of product category and fun brand beliefs was marginally so $(b=-.13, t=-1.85, p=.065)$. These data suggest that contingencies of these effects on social consequences are reliable. Because chips and cookies were coded as -1 and +1 , respectively, the Negative Experiment $\times$ Category $\times$ Fun Belief interaction $(b=-.13)$ and the Positive Experiment $\times$ Category $\times$ Sophistication Belief interaction $(b=.16)$ indicate that the differential effects of fun-related brand image beliefs on intentions to purchase chips, and of sophistication-related beliefs on intentions to buy cookies, were greater when social and impression management needs are high than when they were low. Both of these results are consistent with $\mathrm{H} 3$.

Note further that these interactions were significant only in analyses of purchase intentions and were not significant in analyses of brand attitudes. We thus have support in this pair of experiments for $\mathrm{H} 4$.

The preceding analyses support the arguments in this article that endorser-reinforced brand image beliefs impact brand preference more strongly when all three of these conditions are met: (a) the purchase and consumption of the brand is socially consequential, (b) the brand image beliefs are relevant and schematically fit the product category concerned, and (c) the effects of the beliefs on brand preferences were reflected in purchase intentions but not brand attitudes.

\section{Analysis of Mediation by Brand Image Beliefs}

The role of brand image beliefs in mediating these endorser effects was tested via two Ordinary Least Squares regression 


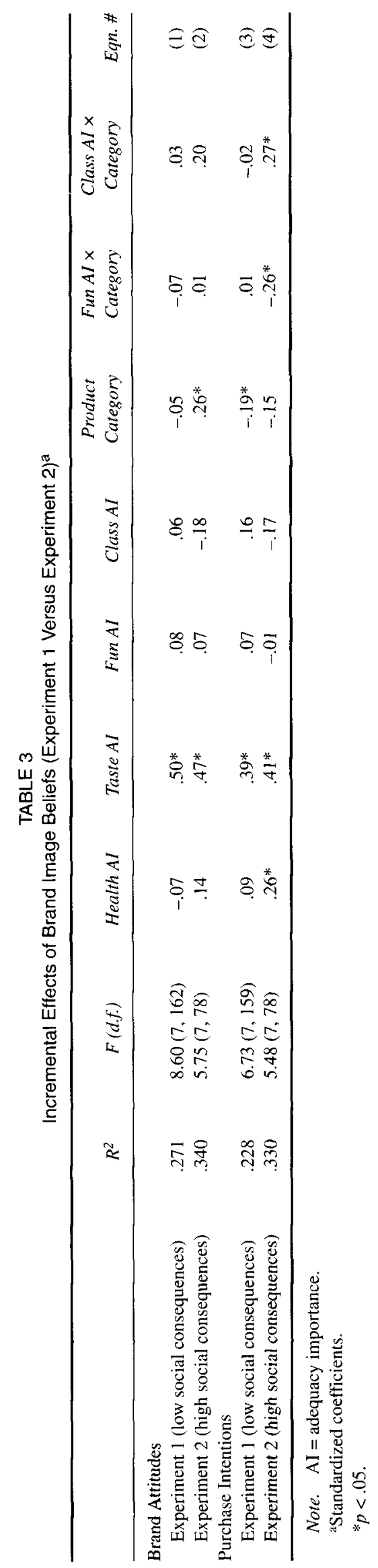

327 
equations. The effect to be tested for possible mediation is the interactive effect of endorser with product category, in the Experiment 2 (high social visibility) data alone. If brand image beliefs mediate this interactive effect, they should reduce the effect of the Endorser $\times$ Category interaction on purchase intentions when they are present, compared to when they are absent. The two equations we compared thus included the interaction effect of endorser with product category, plus the dummy variables for product category and endorser, in predicting purchase intentions. Consistent with Table 3, both these equations also included the health and taste AI beliefs, along with the fun and class AI beliefs (main effects plus interactions with product category). Because the effect of Endorser $\times$ Category on purchase intentions only reached significance earlier when we included prior respondent beliefs about the two endorsers as covariates, we included these as well. Mean-centered data were used to reduce the intercorrelations among the independent variables.

The first equation showed that when brand image beliefs are not in the equation, the Category $\times$ Endorser interaction explains $2.4 \%$ of the variance in purchase intentions over and above the effects of other terms in the equation; incremental $F(1,77)=3.27, p=.07)$. However, introducing image beliefs as covariates, which accounted for $8.6 \%$ of the variance in intentions, reduced the variance accounted for by the aforementioned interaction to only .5\%; incremental $F(1,70)=$ $.76, n s$. This pattern of results supports the mediating role of brand image beliefs.

\section{GENERAL DISCUSSION}

The voluminous prior research on the use of celebrities in advertising (e.g., Kahle \& Homer, 1985; Kamins, 1990) has not looked at the effects of such advertising on the brand image beliefs and perceptions held by consumers. To our knowledge, this study provides the first experimental evidence that ads can indeed "transfer cultural meaning" from ad characteristics (such as endorser personality) to brands, even when the personality assertions are not communicated verbally and explicitly. Thus, it supports the influential (but untested) "meaning transfer" model of McCracken (1986, 1989). Previous studies (e.g., Aaker, 1999, Study 2) used verbal, explicit "brand concept statements" to reinforce the desired personality of the manipulated brands. The indication that this result occurred for class/sophistication but not for fun (H1) is most likely a result of the fact that the company making Ruffles (Frito Lay) was itself rated very high on fun, reducing the strength of our endorser manipulation of this characteristic.

Second, this study established the important moderating role of product category schemas in both the reinforcement of brand image beliefs ( $\mathrm{H} 1)$ and of their consequences for brand preference $(\mathrm{H} 2)$. This is a very useful complement to the recent results of Aaker (1999), who showed the important moderating role of consumer self-schema. Although this need to create category-relevant brand image beliefs may seem intuitively obvious in hindsight, it has not been highlighted before in the brand-building literature that we cited earlier.

Third, consistent with prior research (e.g., Gangestad \& Snyder, 1985), this study showed that ad-evoked brand image beliefs have a greater influence on brand purchase intentions when a "high social consequences" context is evoked (H3). This result makes intuitive sense. In evaluating our findings, it is important to note that our manipulation of social consequences might have had a direct impact on the relevance of product categories for the usage occasion (chips, if partying undergraduate students care more about fun, or cookies, if they care more about impressing others with their sophistication). In addition, because our experiments were not run simultaneously, the difference between them in social consequences may possibly be confounded with possible differences in social responsibility or other variables, though any such effects are not likely to seriously compromise the conclusions drawn. Thus, it seems reasonable to conclude that the creation and impact of brand image beliefs depends on the situational relevance of the cultural meaning benefits they provide to the consumption schema at hand.

Fourth, this study suggests that brand image beliefs make a significant incremental contribution to ad-induced effects on brand purchase intentions over and above functional beliefs. Consistent with Hypothesis 4, however, these incremental brand image beliefs did not emerge for brand attitudes. As discussed earlier, this may be because brand attitudes reflect a consumer's private/internal evaluations and feelings about an object itself, whereas purchase intentions toward it reflect evaluations and feelings toward the act of buying it publicly.

It is especially interesting to note that in this study these belief-building effects occurred through manipulations of the nonverbal elements of the ads (pictures of the endorsers). Thus, the relevant beliefs (about the brand being fun, sophisticated, etc.) were not explicitly (verbally) stated in the ad but were instead inferred by the consumer. It seems incredible, but it is true, that even though a great proportion of communication is said to occur through such nonverbal means (cf. Siegman \& Feldstein, 1987), relatively few academic consumer research studies have studied the processes, or the impact, of such nonverbal creation of inferential beliefs. We also need to better understand the processes through which these nonfunctional beliefs get formed or changed. An advertiser's message about the social usage context of a brand, the kind of user the brand is for, and the kind of user personality that the brand communicates, are likely to be symbolically and associatively implied, rather than explicitly stated. Even when a certain kind of product meaning could be explicitly and verbally asserted in an ad, it may be rhetorically more advantageous to imply that meaning instead. A more precise understanding of the process by which consumers infer 
brand claims from the nonverbal elements in an ad appears desirable.

\section{Limitations}

We were able to obtain these results with just one exposure, for an existing brand. This methodological choice cost us experimental power. Outside the laboratory, however, where consumers see several repetitions and variations of a message, the effects we observed might be magnified. It would be desirable in future studies to use higher levels of frequency and/or exposure time, and also to incorporate the effects of prior consumer brand attitudes into the analysis, something we failed to do. Future studies might also choose to use new brands instead of existing ones like we did, as well as go beyond the standard laboratory context that we used. They ought also to use additional measures beyond the ones we used, such as additional control measures of endorser expertise or likableness. Effects could be measured not just on purchase intentions, but also on actual, publicly visible, purchases. This might show even more clearly the moderating effects of "social consequences."

\section{Future Research}

We chose to study fun and sophistication brand imagery brand beliefs because our pretests showed them to be the two most relevant to the food/snack products category being investigated. It is possible that hedonic brand image beliefs such as fun or cheerful are conceptually close to the ad-evoked affective responses studied by Batra and Ray (1986), Edell and Burke (1987), and Holbrook and Batra (1987), such as an ad putting a consumer in a fun mood. It is widely agreed that affective responses are moods and emotions (such as happiness or sadness) generated with minimal cognitive engagement (not requiring motivation or ability; MacInnis \& Jaworski, 1989). Thus, at least part of the effect of an endorser's fun personality on brand preference might work via these less cognitive mechanisms.

In contrast, the process by which cultural meanings such as class/sophistication are created by ads is probably more deliberative and interpretive, requiring the active cognitive participation of the targeted viewer (McQuarrie \& Mick, 1992; Scott, 1994). The signs in ads operate as cultural codes, and possess meanings only within particular subcultures, and in the context of and in combination with, other signs. For ads to create beliefs about class/sophistication, therefore, consumers must process them with sufficiently high ability and motivation, because such brand image beliefs must be co-constructed by the viewer/reader through an active meaning-creation process (Mick \& Buhl, 1992). This is very different from the automatic, uninvolved processes, in current models of advertising effectiveness, through which affective responses are presumed to exert influence. Such an argument would suggest that affectively toned brand image beliefs (e. g., "cheerful," "warm," "friendly," and "fun" might be qualitatively different from those such as "classy" and "sophisticated." This line of inquiry calls for further research.

\section{ACKNOWLEDGMENTS}

We acknowledge the help of the reviewers in improving this article. The second author acknowledges the support of the California State University, Long Beach Scholarly and Creative Activities Committee.

\section{REFERENCES}

Aaker, D. A. (1991). Managing brand equity, New York: Free Press.

Aaker, J. L. (1997). Dimensions of brand personality. Journal of Marketing Research, 24, 347-356.

Aaker, J. L. (1999). The malleable self: The role of self-expression in persuasion. Journal of Marketing Research, 36, 45-57.

Ahtola, O. T. (1975). The vector model of preferences: An alternative to the Fishbein Model. Journal of Marketing Research, 12, 52-59.

Badenhausen, K. (1996, July 8). Blind faith. Financial World, pp. 50-55.

Batra, R., Lehmann, D. R., \& Singh, D. (1993). The brand personality component of brand goodwill: Some antecedents and consequences. In D. A. Aaker \& A. Biel (Eds.), Brand equity and advertising (pp. 83-96). Hillsdale, NJ: Lawrence Erlbaum Associates, Inc.

Batra, R., \& Ray, M. L. (1986). Affective responses mediating acceptance to advertising. Journal of Consumer Research, 13, 234-249.

Bearden, W. O., \& Etzel, M. J. (1982). Reference group influence on product and brand purchase decisions. Journal of Consumer Research, 9, [83-194.

Bearden, W. O., Netemeyer, R. G., \& Teel, J. E. (1989). Measurement of consumer susceptibility to interpersonal influence. Journal of Consumer Research, 15, 473-481

Belk, R. W. (1988). Possessions and the extended self. Journal of Consumer Research, 15, 139-168.

Cleary, D. P. (1981). Great American brands. New York: Fairchild.

Darden Graduate School of Business Administration, (1990). Absolut Vodka, Case No. UVA-M-336, University of Virginia, Charlottesville, VA.

Domzal, T. J., \& Kernan, J. B. (1992). Reading advertising: The what and how of product meaning. Journal of Consumer Marketing, 9, 48-64.

Durgee, J. F., \& Stuart, R. W. (1987). Advertising symbols and brand names that best represent key product meanings. Journal of Consumer Marketing, 4, 15-24.

Edell, J. A., \& Burke, M. C. (1987). The power of feelings in understanding advertising effects. Journal of Consumer Research, 14, 421-433.

Fishbein, M., \& Ajzen, I. (1975). Belief, attitude, intention, and behavior: An introduction to theory and research. Reading, MA: Addison-Wesley.

Gangestad, S., \& Snyder, M. (1985). To carve nature at its joints': On the existence of discrete classes in personality. Psychological Review, 92, 317-349.

Holbrook, M. B. (1978). Beyond attitude structure. Journal of Marketing Research, 15, 546-556.

Holbrook, M. B., \& Batra, R. (1987). Assessing the role of emotions as mediators of consumer responses to advertising. Journal of Consumer Research, 14, 404-420.

Hovland, C. I., Janis, I. L., \& Kelley, H. H. (1953). Communication and persuasion. New Haven, CT: Yale University Press. 
Kahle, L. R., \& Homer, P. M. (1985). Physical attractiveness of the celebrity endorser: A social adaptation perspective. Joumal of Consumer Research, 11, 954-961.

Kamins, M. A. (1990). An investigation into the "match-up" hypothesis in celebrity advertising: When beauty may be only skin deep. Journal of Advertising, 19(1), 4-13.

Keller, K. L. (1993). Conceptualizing, measuring, and managing customer-based brand equity. Journal of Marketing, 57, 1-22.

Lautman, M. R. (1991). End-benefit segmentation and prototypical bonding. Journal of Advertising Research, 31(3), 9-18.

Lefkoff-Hagius, R., \& Mason, C. H. (1993). Characteristic, beneficial, and image attributes in consumer judgments of similarity and preference. Journal of Consumer Research, 20, 100-110.

Levy, S. J. (1981). Interpreting consumer mythology: A structural approach to consumer behavior. Journal of Marketing, 45, 49-61.

Levy, S. J. (1986). Meanings in advertising stimuli. In J. Olson \& K. Sentis (Eds.), Advertising and consumer psychology (pp. 214-226). Westport, CT: Praeger.

Lynch, J. G., Marmorstein, H., \& Weigold, M. F. (1988). Choices from sets including remembered brands: Use of recalled attributes and prior overall evaluations. Journal of Consumer Research, 15, 169-184.

MacInnis, D. J., \& Jaworski, B. J. (1989). Information processing from advertisements: Toward an integrative framework. Journal of Marketing, $53,1-23$.

McCracken, G. (1986). Culture and consumption: A theoretical account of the structure and movement of the cultural meaning of consumer goods. Journal of Consumer Research, 13, 71-84.

McCracken, G. (1989). Who is the celebrity endorser? Cultural foundations of the endorsement process. Journal of Consumer Research, 16, 310-21.

McCracken, G. (1990, September). Advertising from a cultural point of view: One approach to the gain ad. Paper presented at the Annual Conference of the Association for Consumer Research, New York.
McQuarrie, E. F., \& Mick, D. G. (1992). On resonance: A critical pluralistic inquiry into advertising rhetoric. Journal of Consumer Research, 19, 180-197.

Mick, D. G. (1986). Consumer research and semiotics: Exploring the morphology of signs, symbols, and significance. Journal of Consumer Research, 13, 196-213.

Mick, D. G., \& Buhl, C. (1992). A meaning-based model of advertising experiences. Journal of Consumer Research, 19, 317-338.

Myers, J. H., \& Shocker, A. D. (1981). The nature of product-related attributes. In J. S. (Ed.), Research in marketing (Vol. 5, pp. 211-236). Greenwich, CT: JAI.

Randazzo, S. (1993). Mythmaking on Madison Avenue. Chicago: Probus

Scott, L. M. (1994). The bridge from text to mind: Adapting reader-response theory to consumer research. Journal of Consumer Research, 21,461-480.

Shimp, T. A. (1991). Neo-Pavlovian conditioning and its implications for consumer theory and research. In T. S. Robertson \& H. H. Kassarjian (Eds.), Handbook of consumer theory and research (pp. 162-187). Englewood Cliffs, NJ: Prentice Hall.

Siegman, A. W., \& Feldstein, S. (Eds.) (1987). Nonverbal behavior and communication (2nd ed.). Hillsdale, NJ: Lawrence Erlbaum Associates, Inc.

Snyder, M., \& DeBono, K. G. (1985). Appeals to image and claims about quality. Journal of Personality and Social Psychology, 49, 586-597.

Tetlock, P., \& Manstead, A. S. (1985). Impression management versus intrapsychic explanations in social psychology: A useful dichotomy? Psychological Review, 92(1), 59-77.

Wilkie, W. L., \& Pessemier, E. A. (1973). Issues in marketing's use of multi-attribute models. Journal of Marketing Research, 10, 428-441.

Yi, Y. (1990). On the evaluation of main effects in multiplicative regression models. Journal of the Market Research Society, 31(1), 133-138.

Received: May 2, 2003

Accepted: October 23, 2003 